\title{
Experimental evaluation of the effect of soil water fluctuations in the dynamic behavior of machines
}

\author{
Marcelo Miranda Cremaschi ${ }^{1} \cdot$ Daniella Escribano Leiva ${ }^{2} \cdot$ Pedro Saavedra González $^{1} \cdot$ Cristián Molina Vicuña $^{1}$ (i)
}

Received: 29 August 2020 / Accepted: 12 March 2021 / Published online: 6 April 2021

(C) The Author(s) 2021 OPEN

\begin{abstract}
In this study the dynamic response of a machine-foundation-soil system was investigated experimentally and theoretically. The objective of this work is to analyze the effects of the water table fluctuations in the soil on the response of the foundation and machine subjected to dynamic loads at frequencies ranging from 30 to $50 \mathrm{~Hz}$. A physical model test was developed to simulate a machine-foundation-soil system, with measurements of the machine vibrations and the shear wave velocity of the soil. It is found that the water level produced significant changes in the shear wave velocity of the soil and, thus, in the natural frequencies of the system. For a fully saturated soil the vibration levels increased due to a working condition near resonance. The results showed a good agreement between the experimental vibration measurements and the predictions based on the theory used in foundation design, when considering the appropriate soil parameters. It is concluded that proper estimation of soil parameters is of high importance in the design process of machine foundations.
\end{abstract}

Keywords Machine foundations · Dynamic response - Natural frequency

\section{List of symbols}

C Damping coefficient $(\mathrm{N} / \mathrm{m} / \mathrm{s})$

$F \quad$ Dynamic force $(\mathrm{N})$

$G$ Shear modulus $\left(\mathrm{N} / \mathrm{m}^{2}\right)$

$D$ Damping ratio

$h$ Vertical distance between the center of mass of the system and the center of area of the base of the foundation (m)

1 Moment of inertia of area with respect to the $x$-axis $\left(\mathrm{m}^{4}\right)$

$k$ Stiffness coefficient $(\mathrm{N} / \mathrm{m})$

$m$ Mass $(\mathrm{kg})$

$M$ Dynamic moment (Nm)

$\checkmark$ Volume $\left(\mathrm{m}^{3}\right)$

$V_{s} \quad$ Shear wave velocity $(\mathrm{m} / \mathrm{s})$

$\rho$ Density $\left(\mathrm{kg} / \mathrm{m}^{3}\right)$
$\Omega$ Operating frequency (CPM)

$S$ Degree of saturation (\%)

\section{Introduction}

The foundations of machines such as motors, compressors, fans, and others, play an important role in industry. The vibrations produced by these machines must be kept under permissible values to avoid large settlement of the foundation. Also vibration levels need to be monitored to ensure adequate performance of the machine. To achieve a safe operation of the machine, it is important to correctly design its foundation, for which is important to take the dynamic response of the soil into account. Overall, the complexity of machine foundation design arises from the

Cristián Molina Vicuña, crimolin@udec.cl; Marcelo Miranda Cremaschi, marcelomiranda@udec.cl; Daniella Escribano Leiva, descri bano@udec.cl; Pedro Saavedra González, psaavedr@udec.cl| 'Department of Mechanical Engineering, Universidad de Concepción, Edmundo Larenas 219, Concepción, Chile. ²Department of Civil Engineering, Universidad de Concepción, Edmundo Larenas 219 , Concepción, Chile. 
complex loading conditions, and the interaction between the machine, foundation, and soil (Fig. 1).

Several studies have focused their attention on the vibrations generated by the system and their effects on the foundations. For the dynamic design of the machine foundation, it is necessary to consider the machine features (weight, size, dynamic forces), as well as the features of the soil (stress state, density, dynamic properties). In this aspect, it is essential to analyze the machine, foundation andsoil as a complete system, thus considering theirinteraction. Reported cases have shown the importance of an appropriate study of the soil properties beneath the machine foundation, and the effects of pore pressures on the soil-structure interaction [1-3].

The dynamic performance of the machine-foundationsoil system is highly dependent on the soil conditions and its dynamic properties [4]. The complex dynamic loads applied by machines to the soil may generate strain amplitudes that are not necessarily in the elastic range. In addition, it is well known that soil is highly nonlinear, and the dynamic behavior of the soil depends on the strain level. Previous studies have found that a saturated sand subjected to a vertical force loading causes an increase in natural frequency and a reduction in amplitude [5]. The effect of the degree of saturation $S$ on the dynamic properties of a sand were studied by Livaoglu and Dogangun [6]. The previous authors found that the dynamic properties $G$ and $D$ were independent of changes in $S$ between 25 and $75 \%$, and for $S$ values close to $100 \%$ (fully saturated sand), shear modulus decreased and damping ratio increased. Dong and Lu [7] analyzed the influence of soil saturation on the shear wave velocity $V_{S}$ and the elastic shear modulus $G_{0}$ through experimental tests. The authors found that for the same soil $V_{S}$ and $G_{0}$ have their lowest values when the soil is fully saturated, and their highest value when the soil was dry. Under dynamic loads, a fully saturated soil may experience excessive pore water pressures, which could lead to soil stiffness degradation.

The most accepted theory used in machine foundation design is the elastic half-space theory, where the soil input

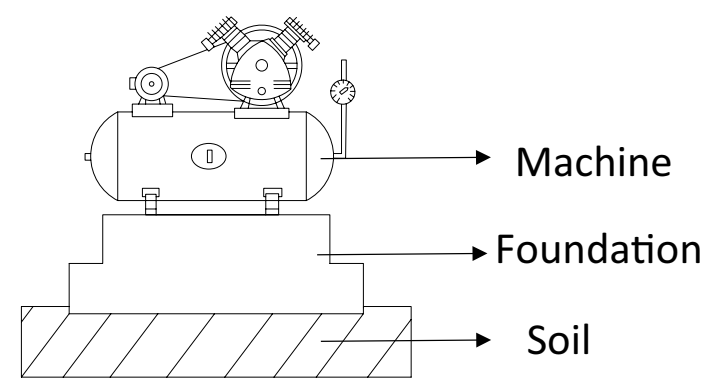

parameters are the shear modulus, Poison's ratio and density [8]. Further studies have been able to consider soil as a stratified half-space and different types of foundation geometries $[9,10]$. The previous theory considers the soil as an elastic and isotropic material.

Among the standards used for machine foundation design are IS 2974 part 1 [11], which provides some general design recommendations; $\mathrm{ACl} 351$. 3R-04 [12] directed to the design of foundations for reciprocating machines. In the same way, standard IS 2974 part 2 [13] is used for impact machines; and the standard IS 2974 part 3 [14] for rotatory machines.

The aim of this study is to analyze the effects of water table fluctuations on the response of a machine foundation subjected to dynamic loads. Through physical model tests of a machine foundation the dynamic properties of the soil were monitored for possible changes. The experimental results are compared to those obtained by current methods used in practice for the analysis of vibrations of machine foundations.

\section{Theoretical framework and modelling}

The foundation is represented as a system of six degrees of freedom. Hence it has six modes of vibration, three of them are translational, and the other three are rotational (Fig. 2).

The model for the system has the following considerations:

- The soil is represented as a system of springs and equivalent damping located in the center of the base area of the foundation;

- The eccentricity between the combined center of gravity of the machine and foundation, and the center area of the base cannot exceed $5 \%$ of the dimensions of the base. The eccentricity and dimensions for each axis are compared and if this restriction is met, it is possible to disregard the combined effect of two or more degrees of freedom [11].

With these considerations it is possible to separate the six degrees of freedom system into two 1-DoF systems and two 2-DoF systems

$$
m \ddot{z}+c_{z} \dot{z}+k_{z} z=F_{z} \cos (\Omega t)
$$

Fig. 1 Machine/foundation/soil system 


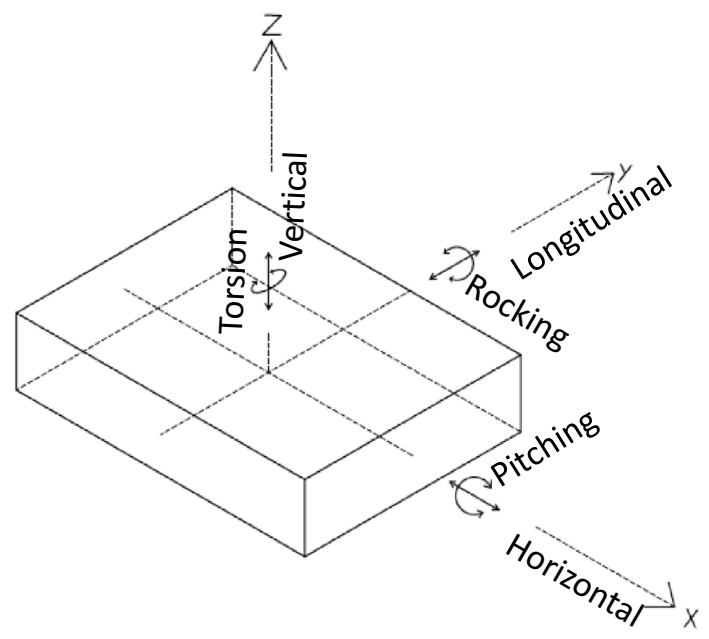

Fig. 2 Vibration modes of the foundation

$I_{z} \ddot{\phi}+c_{\phi} \dot{\phi}+k_{\phi} \phi=M_{\phi} \sin (\Omega t)$

$\left[\begin{array}{cc}m & 0 \\ 0 & l_{\psi}\end{array}\right]\left\{\begin{array}{l}\ddot{x} \\ \ddot{\psi}\end{array}\right\}+\left[\begin{array}{cc}c_{x} & -c_{x} h \\ -c_{x} h & c_{x} h^{2}+c_{\psi}\end{array}\right]\left\{\begin{array}{l}\dot{x} \\ \dot{\psi}\end{array}\right\}$

$+\left[\begin{array}{cc}k_{x} & -k_{x} h \\ -k_{x} h & k_{x} h^{2}+k_{\psi}\end{array}\right]\left\{\begin{array}{c}x \\ \psi\end{array}\right\}=\left\{\begin{array}{c}F_{x} \sin (\Omega t) \\ M_{\psi} \sin (\Omega t)\end{array}\right\}$

$\left[\begin{array}{cc}m & 0 \\ 0 & I_{\theta}\end{array}\right]\left\{\begin{array}{l}\ddot{y} \\ \ddot{\theta}\end{array}\right\}+\left[\begin{array}{cc}c_{y} & -c_{y} h \\ -c_{y} h & c_{y} h^{2}+c_{\theta}\end{array}\right]\left\{\begin{array}{l}\dot{y} \\ \dot{\theta}\end{array}\right\}$

$+\left[\begin{array}{cc}k_{y} & -k_{y} h \\ -k_{y} h & k_{y} h^{2}+k_{\theta}\end{array}\right]\left\{\begin{array}{l}y \\ \theta\end{array}\right\}=\left\{\begin{array}{c}F_{y} \sin (\Omega t) \\ M_{\theta} \cos (\Omega t)\end{array}\right\}$

\section{Design and assembly of the test bench}

The design of the test bench includes an electric motor and a concrete foundation. The foundation rests on a container filled with sand of known density. A rotor disk was designed to allow the inclusion of a known amount of unbalance. The disk included 12 holes on a circle of $2.7 \mathrm{~cm}$ radius, and was mounted on the motor shaft to generate the centrifugal force that excites the system.
Two accelerometers were mounted on the motor case to measure horizontal and vertical vibrations.

The motor is a squirrel-cage three-phase induction motor of $1 / 4$ HP. Its speed is adjusted by using a variable frequency drive. Due to the small weight of the motor $(4.1 \mathrm{~kg})$ the size of the concrete foundation was limited, as well as the size of the soil container. The motor sizeto-weight ratio was used to design the dimensions of the concrete foundation and of the soil container.

Following the work carried out by Bhattacharya et al. [15], the test bench was designed according to scaling laws, for which a reference installation of a real compressor was chosen. Table 1 shows the dimensions of the designed foundation, compared to the foundation of the reference compressor.

With the dimensions given in Table 1, the adimensional relationships were obtained (Table 2 ). In both tables, it is observed that the machine/foundation weight ratio and the relationship between the foundation dimensions are similar.

The container was fabricated with $3 \mathrm{~mm}$ thickness ASTM A36 steel plates and reinforced with laminated angle profiles, to support the total weight without significant deflection (Fig. 3a). The dimensions of the steel box are given in Table 3. To avoid possible boundary effects on the results, the vertical distance between the base of the foundation and the bottom of the container was 6 times de length of the foundation, and the horizontal

Table 1 Dimensions of model and compressor foundations

\begin{tabular}{llll}
\hline Dimension & Model $[\mathrm{mm}]$ & $\begin{array}{l}\text { Compressor } \\
{[\mathrm{mm}]}\end{array}$ & Scale factor [-] \\
\hline Length & 250 & 4800 & $1: 19.2$ \\
Width & 250 & 4800 & $1: 19.2$ \\
Height & 100 & 1750 & $1: 17.5$ \\
\hline
\end{tabular}

Table 2 Adimensional relationships of the model and compressor

\begin{tabular}{lll}
\hline Relationship & Model [-] & Compressor [-] \\
\hline Long/wide foundation & 1 & 1 \\
Long/height foundation & 2.5 & 2.74 \\
Weight foundation/machine & 3.66 & 3.72 \\
\hline
\end{tabular}


Fig. 3 Test bench: a container; b top view of foundation and motor
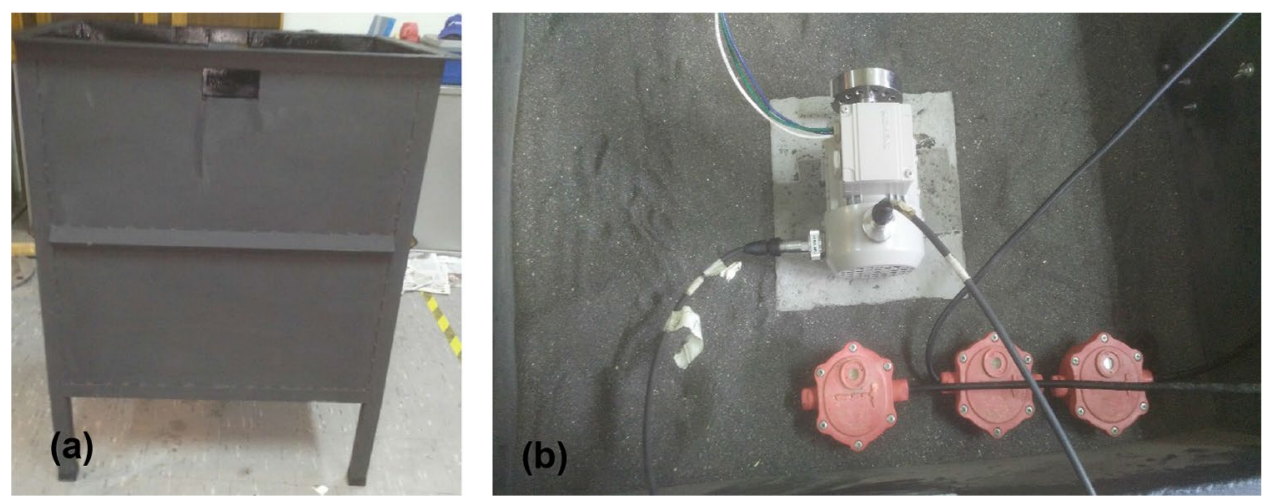

Table 3 Internal container dimensions and amount of sand required

\begin{tabular}{lll}
\hline Dimension & $\begin{array}{l}\text { Steel container dimen- } \\
\text { sions }[\mathrm{mm}]\end{array}$ & $\begin{array}{l}\text { Sand volume } \\
\text { dimensions } \\
{[\mathrm{mm}]}\end{array}$ \\
\hline Length & 850 & 750 \\
Width & 600 & 550 \\
Height & 850 & 600 \\
\hline
\end{tabular}

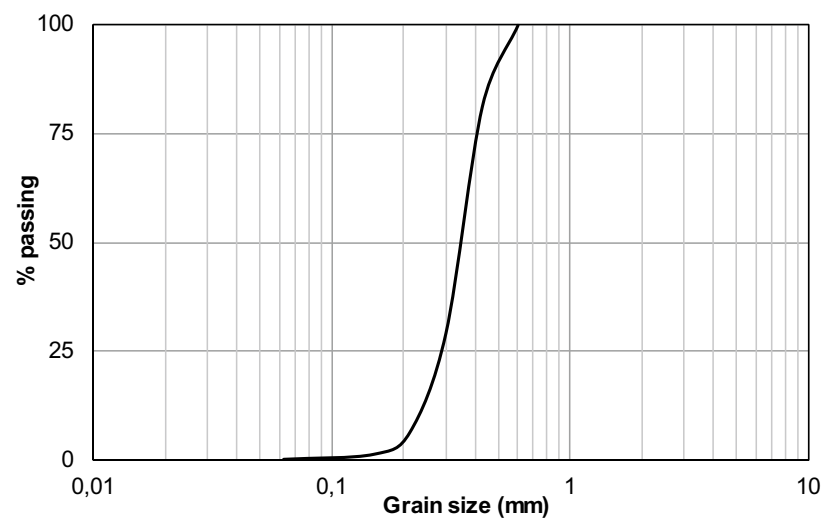

Fig. 4 Particle size distribution of tested sand

distance from the foundation to the boundary of the container was 2 times the foundation length.

\subsection{Characteristics of sand and preparation}

The sand used is locally known as Biobio sand, and it is classified as poorly graded fine grained sand. The particle size distribution of the sand is shown in Fig. 4. The minimum and maximum dry density of the sand is $1782 \mathrm{~kg} / \mathrm{m}^{3}$ and $1458 \mathrm{~kg} / \mathrm{m}^{3}$, respectively.

The sand was deposited inside the container by air pluviation method. The desired density was obtained by controlling the mesh at which the sand passed, and the density was monitored in order to maintain a uniform density until the final layer. The achieved density varied between 50 and $55 \%$ of relative density The saturation process was performed from the bottom of the container through a series of inlets. In this way the pore fluid was distributed evenly at the base of the soil. The saturation process was performed slowly to avoid any disturbance of the soil fabric.

\section{Results}

To determine the dynamic response of the system it is necessary to obtain the dynamic properties of the soil. Through Eq. (5) the shear modulus of the soil $G$ is obtained from the shear wave velocity and bulk density of the soil:

$\mathrm{G}=\mathrm{V}_{\mathrm{s}}^{2} * \rho$

Measurements of $V_{s}$ were achieved by using three biaxial geophones installed at the surface of the soil (Fig. 3). This procedure is based on the refraction microtremor method ReMi and consists of generating an impact-like excitation at the surface of the soil and measuring the resulting Rayleigh waves data through the geophones. As the vibration source generates small strain amplitudes, the soil properties obtained are in the elastic range. The excitation source was produced by dropping a coin in the sand at a collinear point to the three geophones. Each geophone captured the surface waves, allowing an estimate of $V_{s}$.

Figure 5 shows the measured waveforms from the 3 geophones for one test, where the time lag of the traveling wave in the soil can be observed. As the relative distance between the geophones is known, the shear wave velocity can be calculated. With this method the velocity of the Rayleigh wave is obtained which is approximately $90 \%$ of the shear wave velocity (Table 4).

Once $V_{S}$ is obtained and the density of the soil is known, Eq. (5) is used to obtain $G$. The initial shear modulus $G_{0}$ of

\section{SN Applied Sciences}




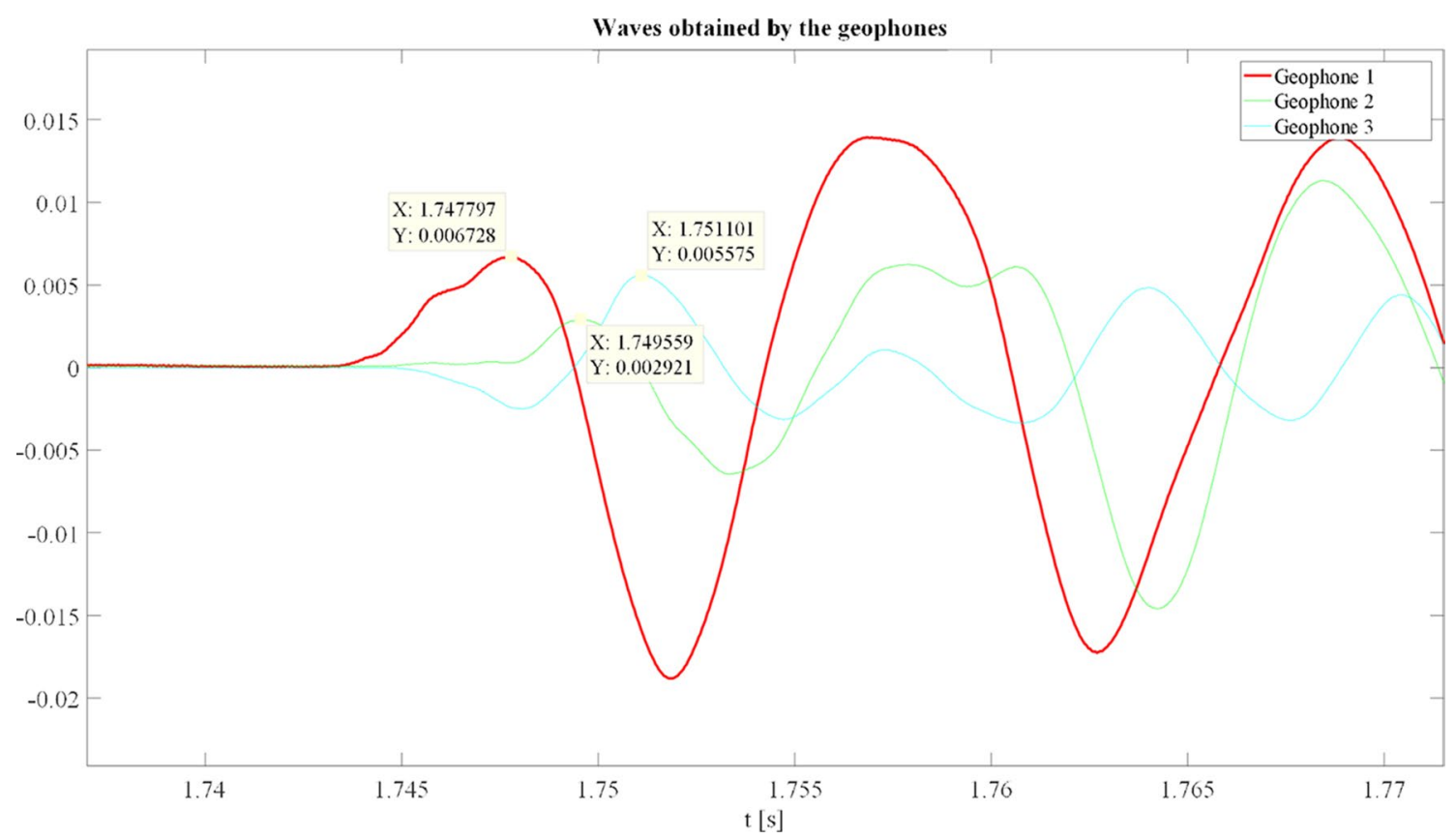

Fig. 5 Shear waves measured by each geophone

Table 4 Initial shear wave velocity

\begin{tabular}{lccc}
\hline $\begin{array}{l}\text { Geophones } \\
\text { combination }\end{array}$ & Distance [m] & $\begin{array}{l}\text { Vertical shear } \\
\text { wave velocity } \\
{[\mathrm{m} / \mathrm{s}]}\end{array}$ & $\begin{array}{l}\text { Horizontal shear } \\
\text { wave velocity } \\
{[\mathrm{m} / \mathrm{s}]}\end{array}$ \\
\hline Geo1-Geo2 & 0.145 & 126.52 & 82.29 \\
Geo2-Geo3 & 0.145 & 78.38 & 94.03 \\
Geo1-Geo3 & 0.290 & 96.70 & 96.7 \\
Average & & 100.53 & 91.01 \\
\hline
\end{tabular}

the soil in the horizontal direction was $159 \mathrm{MPa}$, and in the vertical direction was $193 \mathrm{MPa}$.

The theory presented by Gazzetas [10] was used to obtain the stiffness and damping coefficients of the soil supporting the foundation. By obtaining these coefficients it is possible to completely define the equations of motion and solve them as presented in Sect. 2.

Three experimental cases were considered to analyze the influence of the water table on the behavior of the machine/foundation system. The first case corresponds to completely dry soil, the second case corresponds to infiltrations of water up to a height of $500 \mathrm{~mm}$ (at the base of the foundation) and the third case corresponds to a fully saturated sand (Fig. 6). For the three cases mentioned, the same procedure was followed: first the shear wave velocity of soil was determined, then the natural frequencies of the system were obtained by the bump test method, and finally, the vibrations coming from the unbalance of the motor were measured by varying its rotating speed between 30 and $50 \mathrm{~Hz}$. All measurements were done for the horizontal and vertical axes.

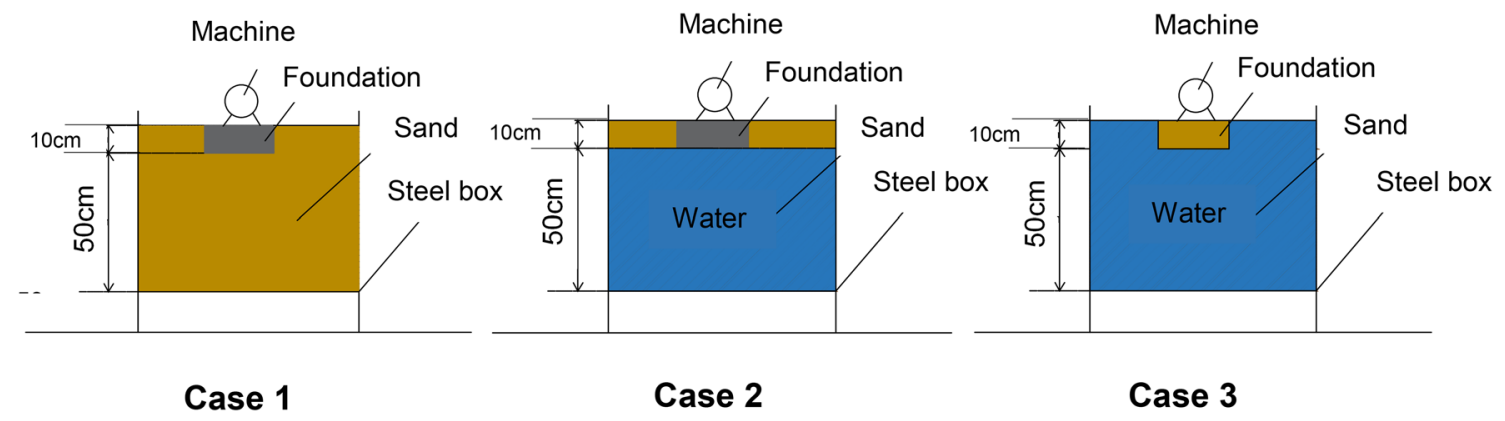

Fig. 6 Three cases of water infiltration studied 
Table 5 Shear wave velocity for each case in Fig. 6 after dynamic load application

\begin{tabular}{lll}
\hline Case & Horizontal $[\mathrm{m} / \mathrm{s}]$ & Vertical $[\mathrm{m} / \mathrm{s}]$ \\
\hline 1 & 112 & 115 \\
2 & $91(-19.64 \%)$ & $90(-21.7 \%)$ \\
3 & $72(-20 \%)$ & $85(-5.55 \%)$ \\
\hline
\end{tabular}

Table 5 shows the magnitudes of horizontal and vertical shear wave velocity for each case after the dynamic load was applied. The percentage between brackets corresponds to the variation with respect to the previous case.

From Table 5 it is clear that the magnitude of $V_{s^{\prime}}$ and therefore of $G_{0}$, decrease with the rise in water table from case 1 to case 3 . The decrease in stiffness could be explained by an increase in the shear strain amplitude experienced by the soil. The increase in shear strain amplitude in a saturated sand during dynamic loading can be caused by impeded drainage of the water in the voids of the sand, producing an excess pore water pressure. The inability of a granular soil to dissipate the excess pore water pressure during dynamic loading is due to the high frequencies applied. Fattah et al. [16] obtained higher excess pore water pressure development for higher operating frequency of a machine foundation resting on saturated sand, and the rate of increase reached its maximum at the resonance frequency. The previous findings agree with studies of $V s$ and $G$ reduction for a fully saturated soil under machine vibrations $[6,7]$.

Figure 7 shows the horizontal and vertical velocity vibration of the motor measured during each test when the motor speed was varied between 30 and $50 \mathrm{~Hz}$. For both directions, the amplitude of vibration increases as the water table rises (from case 1 to case 3 ), and this increment is higher as the speed is increased from 30 to $50 \mathrm{~Hz}$, and more evident in the horizontal direction.

The natural frequency of the machine-foundation system was obtained by the bump-test method. Figures 8 and 9 show the resulting vibration spectra for each case in the horizontal and vertical direction, respectively. In both directions, the rise of the water table generates a decrease in the fundamental natural frequency. Table 6 presents the values of these natural frequencies and the percentage of variation with respect to the corresponding previous case tested.

The results given in Table 6 correlate well with the variation of the shear wave velocity presented in Table 5 . This can be explained by noting that the stiffness coefficient $k$ is directly proportional to its shear modulus

$k=G * C$
Fig. 7 Horizontal and vertical velocities vibration
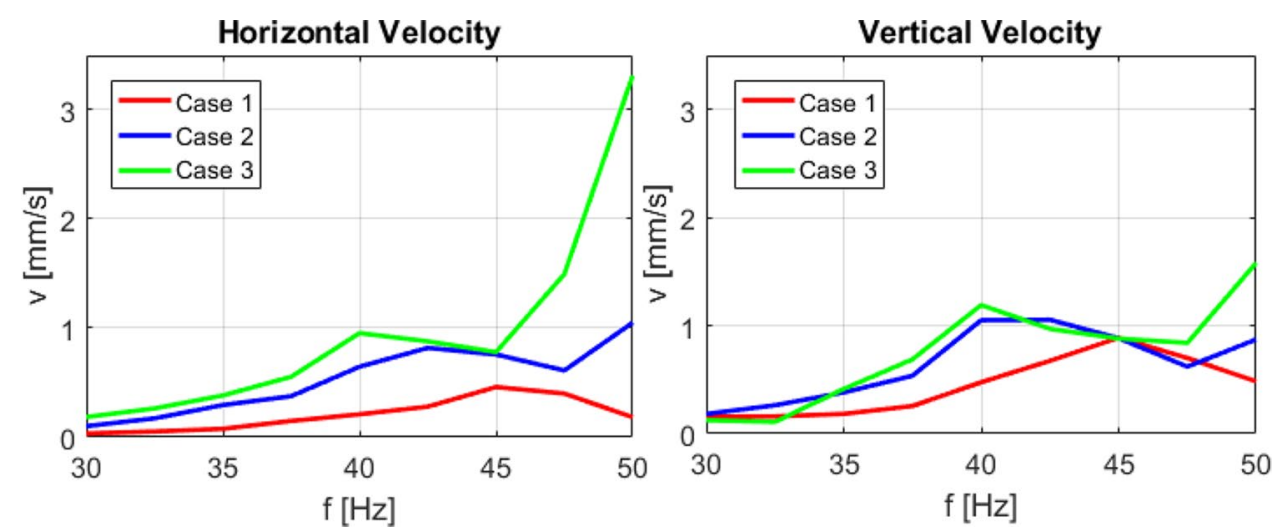
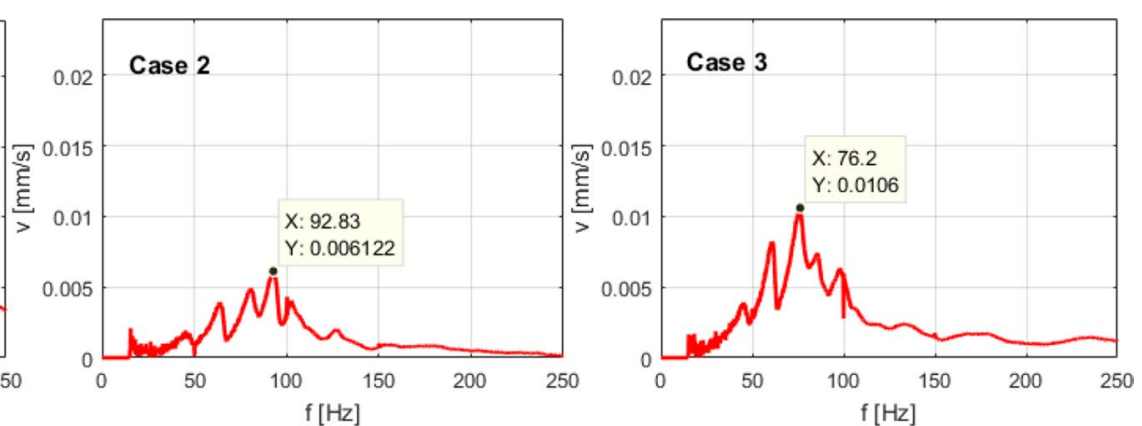

Fig. 8 Horizontal natural frequency 

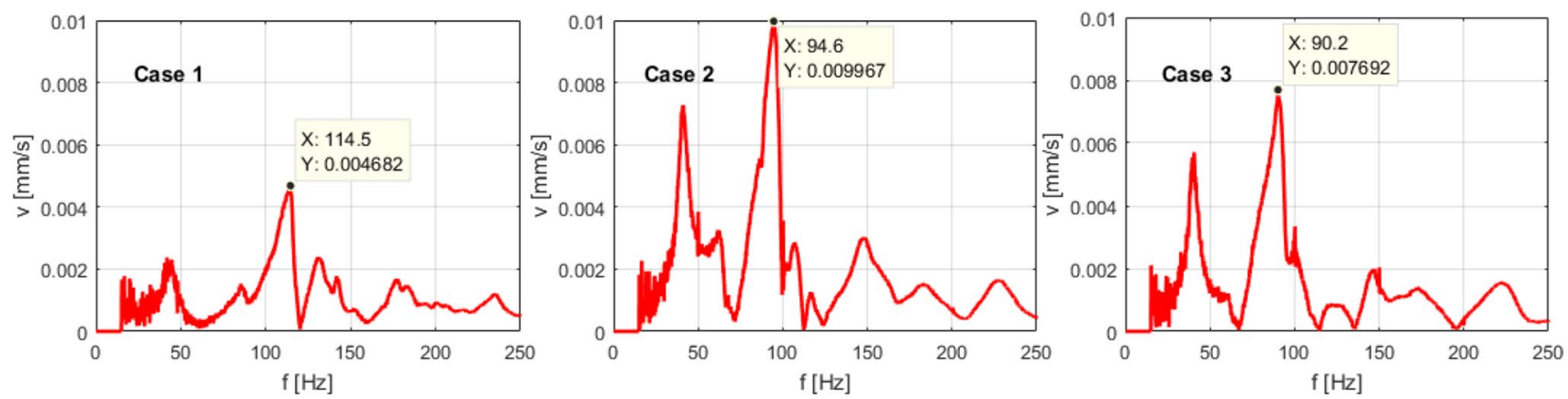

Fig. 9 Vertical natural frequency

Table 6 Natural frequencies of the machine-foundation system

\begin{tabular}{lll}
\hline Case & Horizontal $[\mathrm{Hz}]$ & Vertical $[\mathrm{Hz}]$ \\
\hline 1 & 117.3 & 114.5 \\
2 & $92.8(-20.8 \%)$ & $94.5(-17.47 \%)$ \\
3 & $76.2(-17.9 \%)$ & $90.2(-4.55 \%)$ \\
\hline
\end{tabular}

where $C$ is a proportional constant. As is known, stiffness is one of the parameters defining the natural frequency of the system:

$\omega_{n}=\sqrt{\frac{k}{m}}$

where $m$ is the effective vibrating mass of the system (i.e. the mass of the machine and foundation). Substituting Eqs. (5) and (6) into (7) yields Eq. (8), where the direct relation between the shear velocity and the natural frequency becomes clear.

$\omega_{n}=V_{s} \sqrt{\frac{\rho * C}{m}}$

Next, the results obtained by using the theoretical framework for the design of machine foundations are compared with the experimental vibration measured for each case studied. Figures 10 and 11 show the theoretical and experimental results in the horizontal and vertical directions, respectively. The main differences between the theoretical predictions and the experimental measurements are discussed following.

The first difference is most noticeable in the vertical direction (Fig. 11) and has the shape of resonance with a peak at $45 \mathrm{~Hz}$ in case 1 . This resonant zone changes its frequency when more water is added to the container, reaching $40 \mathrm{~Hz}$ in case 3 , and having an intermediate value in case 2 . This resonant zone corresponds to the mode of vibration of the container as a complete system; that is, the container and its content acting as the vibrating mass and the support of the container as the stiffness element. The resonant frequency lowers as the mass inside the container increase due to the rise of the water table. Since the theoretical model only focuses on the soil, foundation and motor, this vibration mode is not considered, and therefore it is not reflected in the theoretical curves in Figs. 10 and 11.

The second difference is the sharp increase in the vibration level measured when the motor was running at $50 \mathrm{~Hz}$ in case 3, especially in the horizontal direction (Fig. 10). The reason for this vibration increment is the
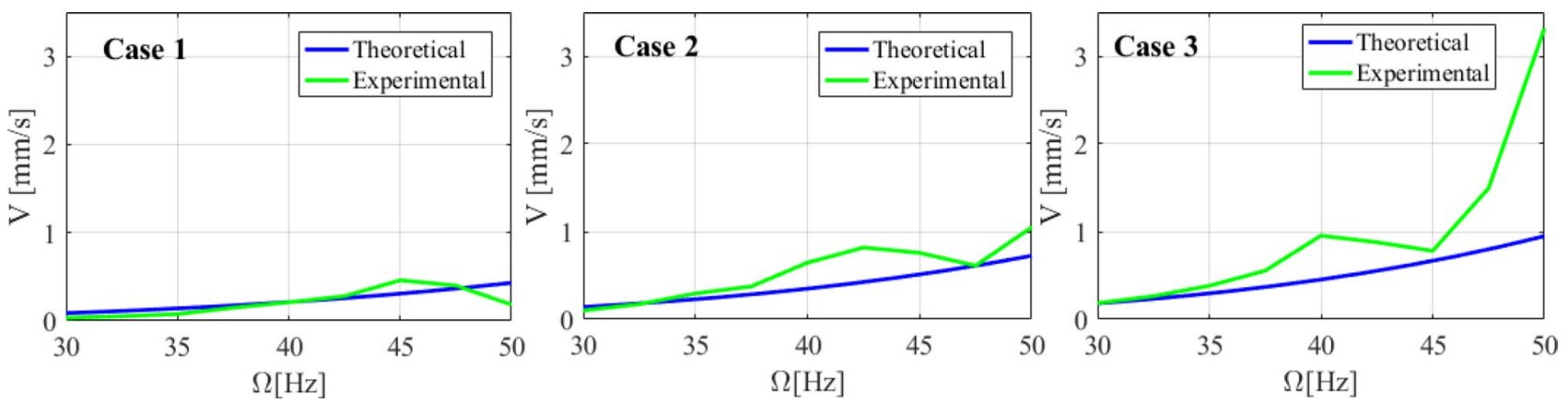

Fig. 10 Theoretical and experimental horizontal velocity vibrations 

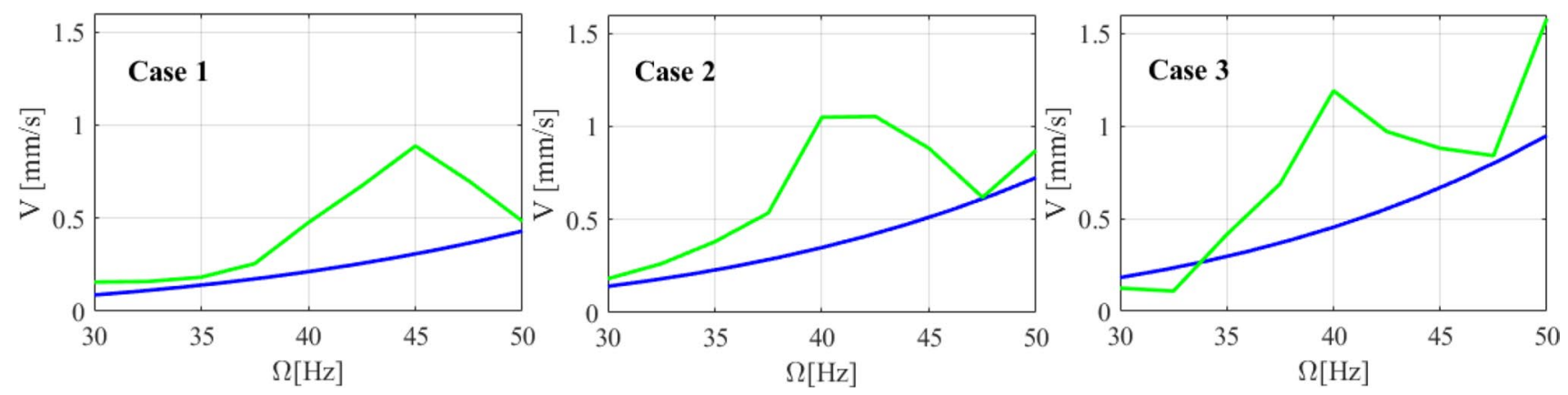

Fig. 11 Theoretical and experimental vertical velocity vibrations

change in the natural frequency of the soil-foundationmotor system due to the higher water level. Figure 8 provides a clear view of the system response in the frequency domain for the three cases. It can be seen how the main resonant zone shifts to the left from case 1 (dry soil) to case 3 (fully saturated soil). As the excitation frequency of $50 \mathrm{~Hz}$ is closer to the resonant zone in case 3, this results in increased vibration levels. In Figs. 10 and 11 it is also noticed that the theoretical curve, although not coincident with the experimental curve, does exponentially increase with the frequency. This means that it is also entering a resonant zone, but whose main frequency is higher. The reason why the measured and theoretical resonant frequency do not match might be due to the response of the container walls or other particularities of the experimental installation not considered by the model.

Apart from the differences stated above, the tendency shown by the theoretical and experimental results in Figs. 10 and 11 are in good agreement. It is also important to recall that this match in the tendency is only possible if the theoretical model includes proper parameters of the soil. That is, the theoretical curves in case 1, 2 and 3 are different only because the dynamic properties of the soil are different in the corresponding models, which in this case is due to the water content of the soil.

In order to ensure a safe and efficient performance of the machine, the natural frequency of the system (Fig. 1) must be kept far from the operating frequency of the machine. The results of this study indicate that as the water table rises from case 1 to 3 there is a decrease in the shear wave velocity of the soil, which correlates with a decrease in the horizontal and vertical natural frequency of the system. These changes may affect the performance of the system in the long term, as it depends on the dynamic behavior of the soil. As well, the rise of the water table in the sand may amplify the vibrations induced by the machine, and this amplification depends on the frequency of operation. The vibration amplification is produced by a decrease in the stiffness of the sand when it is dynamically loaded under a fully saturated state.

\section{Conclusions}

The objective of this work was to analyze the effects of water table fluctuations over the behavior of a machinefoundations-soil system. The experimental results indicate that the water table fluctuations produced changes in the shear wave velocity of the soil and, therefore, in its natural frequency, which decreased in $35 \%$ and $21 \%$ in the horizontal and vertical direction, respectively. When the motor ran at $50 \mathrm{~Hz}$ and the soil was fully saturated (case 3 ), the system worked at a near resonant condition in the horizontal direction and the vibration levels were amplified.

The trend of the vibrations measured experimentally found good correlation with the predictions from the theoretical model for the different frequencies of the motor. This correlation was achieved by considering the 
soil parameters in the theoretical model according to the water table of each case studied. These results point out the importance role of the soil in the design of machine foundations, and that the theoretical model used for this process is able to represent the real situation if the soil parameters are appropriately considered. They also show that, in cases where the soil is constrained, the water level fluctuations may produce changes in the soil properties that affect the dynamic behavior of the system.

\section{Declarations}

Conflict of interest The authors declare that they have no conflict of interest.

Open Access This article is licensed under a Creative Commons Attribution 4.0 International License, which permits use, sharing, adaptation, distribution and reproduction in any medium or format, as long as you give appropriate credit to the original author(s) and the source, provide a link to the Creative Commons licence, and indicate if changes were made. The images or other third party material in this article are included in the article's Creative Commons licence, unless indicated otherwise in a credit line to the material. If material is not included in the article's Creative Commons licence and your intended use is not permitted by statutory regulation or exceeds the permitted use, you will need to obtain permission directly from the copyright holder. To view a copy of this licence, visit http://creativecommons. org/licenses/by/4.0/.

\section{References}

1. Prakash S, Puri VK (1988) Foundations for machines: analysis and design (Chapter 13)

2. Todorovska Ml, Al Rjoub Y (2006) Plain strain soil-structure interaction model for a building supported by a circular foundation embedded in a poroelastic half-space. Soil Dynamics and Earthquake Engineering

3. Vlad I (2010) Machine foundations and blast engineering vibrations case studies. Missouri University of Science and Techhnology

4. Ali OS, Aggour MS, McCuen RH (2017) Dynamic soil-pile interactions for machine foundations. Int J Geotech Eng 11(3):236-247

5. Al-Homoud AS, Al-Maaitah ON (1996) An experimental investigation of vertical vibration of model footings on sand. Soil Dyn Earthq Eng 15(7):431-445

6. Livaoglu R, Dogangun A (2007) Effect of foundation embedment on seismic behavior of elevated tanks considering fluidstructure-soil interaction. Soil Dyn Earthq Eng 27(9):855-863

7. Dong Y, Lu N (2016) Dependences of shear wave velocity and shear modulus of soil on saturation. American Society of Civil Engineers

8. Lamb H (1904) The propagation of tremors over the surface of an elastic solid. Philos Trans R Soc Lond

9. Gazetas G (1975) Dynamic stiffness functions of strip and rectangular footing on layered soil. S. M. thesis: MIT

10. Gazetas G (1991) Formulas and charts for impedances of surface and embedded foundations. American Society of Civil Engineers

11. Standard IS 2974 (1980) Part 1: foundations for reciprocating types machines

12. Standard ACl 351 3R-04 (2004) Foundations for dynamic equipment

13. Standard IS 2974 (1982) Part 2: foundations for impact type machines (hammer foundations)

14. Standard IS 2974 (1993) Part 3: foundations for rotatory type machines

15. Bhattacharya S, Muir D, Lombardi D (2010) Similitude relationships for physical modelling of monopile supported offshore wind turbines. Int J Phys Model Geotech

16. Fattah MY, Al-Mosawi MJ, Al-Americ AFI (2017) Stresses and pore water pressure induced by machine foundation on saturated sand. Ocean Eng 146:268-281

Publisher's Note Springer Nature remains neutral with regard to jurisdictional claims in published maps and institutional affiliations. 